\title{
Tactics of Soft Resistance in User Experience Professionals' Values Work
}

\author{
RICHMOND Y. WONG, University of California, Berkeley, USA
}

User experience (UX) professionals' attempts to address social values as a part of their work practice can overlap with tactics to contest, resist, or change the companies they work for. This paper studies tactics that take place in this overlap, where UX professionals try to re-shape the values embodied and promoted by their companies, in addition to the values embodied and promoted in the technical systems and products that their companies produce. Through interviews with UX professionals working at large U.S.-based technology companies and observations at UX meetup events, this paper identifies tactics used towards three goals: (1) creating space for UX expertise to address values; (2) making values visible and relevant to other organizational stakeholders; and (3) changing organizational processes and orientations towards values. This paper analyzes these as tactics of resistance: UX professionals seek to subvert or change existing practices and organizational structures towards more values-conscious ends. Yet, these tactics of resistance often rely on the dominant discourses and logics of the technology industry. The paper characterizes these as partial or "soft" tactics, but also argues that they nevertheless hold possibilities for enacting values-oriented changes.

CCS Concepts: • Social and professional topics $\rightarrow$ Codes of ethics; Computing occupations; Computing organizations.

Additional Key Words and Phrases: soft resistance; values work; ethics work; values in design; values; ethics; UX professionals; UX practice; work practice

\section{ACM Reference Format:}

Richmond Y. Wong. 2021. Tactics of Soft Resistance in User Experience Professionals' Values Work. Proc. ACM Hum.-Comput. Interact. 5, CSCW2, Article 355 (October 2021), 28 pages. https://doi.org/10.1145/3479499

\section{INTRODUCTION}

In recent years, many workers at large technology companies have taken public actions that resist, contest, and call for changes related to the social values and ethical implications of their companies' products, services, and work environments. For instance, Google workers wrote open letters to their company's management or resigned in protest in response to a contract with the U.S. Department of Defense. ${ }^{1}$ Technology company workers contested their companies' relations and contracts with the U.S. Department of Homeland Security, U.S. Customs and Border Protection, and U.S. Immigration and Customs Enforcement during increased family separations among migrant families during the Trump administration. Employees at a variety of major technology companies wrote open letters

\footnotetext{
${ }^{1}$ https://www.nytimes.com/2018/04/04/technology/google-letter-ceo-pentagon-project.html; https://gizmodo.com/googleemployees-resign-in-protest-against-pentagon-con-1825729300; https://www.theverge.com/2018/6/1/17418406/googlemaven-drone-imagery-ai-contract-expire
}

Author's address: Richmond Y. Wong, ryw9@berkeley.edu, University of California, Berkeley, Center for Long-Term Cybersecurity, Berkeley, California, USA, 94720.

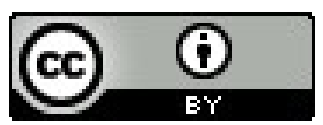

This work is licensed under a Creative Commons Attribution International 4.0 License.

(c) 2021 Copyright held by the owner/author(s).

2573-0142/2021/10-ART355. https://doi.org/10.1145/3479499

Proc. ACM Hum.-Comput. Interact., Vol. 5, No. CSCW2, Article 355. Publication date: October 2021. 
to their executives voicing concerns about providing services or software to these organizations. ${ }^{2}$ Google employees organized a walkout in 2018 in response to a series of events related to sexual discrimination and harassment, advocating for changes such as pay and opportunity equality, and creating clearer and more inclusive processes for reporting sexual misconduct. ${ }^{3}$ More recently, some tech workers in the U.S. are taking steps towards unionization. ${ }^{4}$ Across these examples, tech workers contested and resisted their companies' current practices, advocating for new configurations and relations that would promote a different set of values.

In parallel to these practices, prior empirical research in CSCW and related fields has studied how values and ethics emerge as a part of the everyday work of technology researchers and practitioners [41, 61], data scientists [55], security professionals [42], and user experience (UX) professionals $[12,26]$. Further research has sought to develop new theories, frameworks, methods, and tools to help technology practitioners grapple with a range of social values and ethical issues in their everyday work. This includes incorporating fairness into AI and algorithmic systems $[16,37,48,66]$, addressing issues of privacy and security $[5,18,74]$, considering the needs and well-being of platform workers [17, 35], and avoiding causing and perpetuating harms.

This paper focuses on tech worker practices that lie at the intersection of activism, contestation, and resistance, as well as everyday work that addresses values and ethical issues. It analyzes how some practices of UX professionals' values work (or ethics work)-everyday practices conducted in the name of attending to social values-also serve as tactics of resistance against the conduct of the technology companies they work in. These tactics are analyzed through Nafus and Sherman's concept of "soft resistance" [50], which helps understand the partiality of trying to resist and create change from within systems of power. While organizational power and dominant logics of the technology industry present barriers to creating change, this analytical lens highlights the possibility for some changes to be enacted from frontline positions within technology companies. This paper reports on findings from interviews with UX professionals who work at large technology organizations in the United States and observations of public meetup events about design, values, and ethics in Northern California. It focuses on UX professionals who explicitly see their work as political and values-laden, and who attempt to create changes within their organizations in order to more fully address the social values they wish to promote.

The paper contributes an empirical understanding of the range of tactics that UX professionals use when attempting to enact values and ethics oriented changes within their organizations. The tactics discussed broadly work towards three types of changes: (1) creating space for UX expertise to address values; (2) making values visible and relevant to others in the organization; and (3) changing organizational processes and orientations towards values. However, the UX professionals interviewed report tensions and challenges in trying to enact change from positions of relatively low power within their companies. These tensions reflect the partial nature of these resistance practices. The analytical lens of soft resistance [50] helps show how these partial tactics can nevertheless be useful. This lens also opens up a space for researchers and designers to understand and support the social, political, and organizational practices of UX professionals, not just their technical practices.

\footnotetext{
${ }^{2}$ https://www.nytimes.com/2018/06/19/technology/tech-companies-immigration-border.html; https://www.theverge.com/ 2018/6/25/17504154/salesforce-employee-letter-border-protection-ice-immigration-cbp; https://www.theverge.com/2018/ 6/22/17492106/amazon-ice-facial-recognition-internal-letter-protest; https://www.washingtonpost.com/business/2019/ 08/22/war-inside-palantir-data-mining-firms-ties-ice-under-attack-by-employees/

${ }^{3}$ https://www.vox.com/identities/2017/8/8/16106728/google-fired-engineer-anti-diversity-memo; https://www.bbc.com/ news/technology-46054202; https://www.latimes.com/business/technology/story/2019-11-06/google-employee-walkouttech-industry-activism

${ }^{4}$ https://www.nytimes.com/2021/01/04/technology/google-employees-union.html
} 
In the following sections, the paper presents related work and methods. It then presents findings regarding the types of changes UX professionals seek, the tactics they employ, and tensions in trying to enact these changes. The paper ends by reflecting on the affective experience of soft resistance, the analytical lens of soft resistance, and implications for future values in design research and practice.

\section{RELATED WORK}

This section situates the paper in prior research that studies values in design and how UX professionals approach values and ethical issues in their work. It then introduces Nafus and Sherman's concept of "soft resistance."

\subsection{Values in Design}

Interdisciplinary research under the rubric of "values in design" has long been interested in how technological artifacts and the practices of production promote or embed social values, ethics, and politics, as well as how technology designers' practices and beliefs affect these artifacts $[3,15,52,68]$. Values in Design research in CSCW, HCI, and adjacent fields has sought to analyze how social values are implicated in practices of technology design, creation, maintenance, and repair (e.g., $[26,31,55,62,71])$. From an HCI perspective, value sensitive design provides one framework to elicit and address values while building systems by considering direct and indirect stakeholders; mapping benefits, harms, and values to the different stakeholders; and identifying potential values conflicts $[19,21]$. In addition, researchers have created and evaluated a range of design activities and toolkits to integrate consideration of values into the design process (e.g., [6, 11, 20, 40, 51, 72]). This paper complements these design-led and intervention-oriented studies by studying the work practices of the imagined users of these tools: technology practitioners and UX professionals who self-identify as addressing values as a part of their work.

This project follows the call of Gürses and Hoboken to study values and ethics in the context of technology production, as "inquiries into their production can help us better engage with new configurations of power that have implications for fundamental rights and freedoms." [28]. It also builds on prior work studying practices or "levers" that help technologists and engineers surface values and make them salient for action [61].

This paper seeks to understand how tactics of resistance and contestation emerge in technology professionals' everyday work practices addressing values. This project conceptualizes social values as lenses or hypotheses that shape action [54]. Consistent with perspectives that view values as situated and part of everyday experiences [36, 62], there is not a single universal set of social values that UX professionals seek to promote. Rather, UX professionals act in relation to social values issues that arise in specific situations in their work (although these North American participants may more often recognize and promote values in line with Western cultural expectations). I refer to the practices that practitioners conduct in the name of values as values work. This could include practices such as advocacy [60], designing, information seeking and sharing, agenda setting, or building and maintaining social relationships.

\subsection{Values and Ethics in UX and Organizational Practices}

As technology companies face pressure to address social values and ethical issues, many have begun to hire or assign people in the role of "ethics owners"-people who hold responsibility for addressing ethics by overseeing integration of ethics across the organization and its multiple divisions or hierarchies [43]. These are often executive, managerial, or supervisory roles. In contrast to these ethics owners, UX professionals work closer to the "front lines" or "on the ground" of an organization. Prior organizational studies have shown gaps between workers' understanding 
of their own work practices and management's conception of their work [53, 75]. Similarly, UX professionals may attempt to address values and ethical issues in ways different from what is envisioned by ethics owners who are closer to the top of the organization.

UX professionals present a unique perspective among those involved in technology production from which to think about the politics and values of artifacts, as their roles integrate consideration of technical and social factors. In seeking to understand UX professionals' values work in particular, this project builds on prior research which has found that UX professionals' work in general involves social and political practices (as well as technical ones). Designers deploy rhetorical and discursive strategies when presenting their arguments and design ideas to other organizational stakeholders [22, 56], and UX practitioners are expected to learn how to navigate corporate cultures and bureaucracies, and to communicate ideas by picking up new design tools [25]. Prior research has also studied the politics of UX professionals' practices, including how they construct the category of "user" [73], the politics of user centered design practices [23, 32, 67], or how user researchers frame their work in order to fit within engineering and marketing frameworks of practice and knowledge [49]. These studies show how general UX work is not just the "technical" work of research and design, but is also deeply social and political.

Research studying the values and ethics work of technologists highlights how organizational politics, processes, and power dynamics affect workers' practices. Shilton discusses how process like funding and IRB mandates at an academic institution can surface discussion of values among technologists [61]. Madaio et al. co-design tools for fairness with technology practitioners, highlighting how changes in organizational culture-such as in organizational goals and priorities-are needed to fully address issues of fairness; new tools and checklists on their own do not necessarily lead to values concerns being listened to and addressed by decision-makers [41]. Gray et al. write that designers' ethical practices shape and are shaped by their individual practices, by organizational practices, and by knowledge and reasoning built through education [26]. Chivukula et al. find that the positionality of user experience in an organization, such as the extent to which UX professionals are valued, affects the extent to which they can surface and address ethical issues [12].

This paper's empirical research provides new sites and entry points to study values work, building on prior research: participants are recruited from positions within established or large technology companies, compared to Shilton's study of technical practitioners in academic labs [61] or Gray et al.'s broader focus that includes UX professionals at design agencies or consultancies [26]. UX professionals working in-house within established or large corporations are likely to face different types of power dynamics in their work.

Furthermore, this paper's analytical perspective complements prior research that focuses on values and ethics emerging as a part of everyday work practices. While the technologists in these studies must navigate organizational constraints as a part of their everyday practices, these studies tend to focus on how technology professionals work to change or create products or systems in ways that reflect the social values and ethics that they wish to promote. This paper looks at a different set of goals: how UX professionals work from within to try to change or create an organization with values that they wish to promote, through attempts at organizational change, contestation, and resistance. This connects practices of everyday work to broader practices of technology worker criticism, contestation, and resistance [64]. To recruit people who might involved in seeking these types of changes, this paper recruits UX professionals who explicitly see their work as political and values laden, and work within established or large technology companies in the United States, compared to other projects that seek to sample a broader set of UX professionals [12]. 


\subsection{Soft Resistance}

This paper analyzes UX professionals' practices that seek to contest or change how work is conducted in their organizations in relation to values and ethics. While UX professionals generally have well-paid positions and work for technology companies that give them some social status, within their organizations they often lack decision-making power. UX knowledge is not always viewed as legitimate or important, and UX professionals tend to work further down in the organizational structure.

When analyzing resistance practices within organizations, I draw on the concept of "soft resistance" as articulated by Dawn Nafus and Jamie Sherman in the context of Quantified Self users:

Soft resistance happens when participants assume multiple roles as project designers, data collectors, and critical sense-makers, rapidly assessing and often changing what data they collect and why in response to idiosyncratically shifting sets of priorities and objectives. [...] We posit this resistance as "soft" as a way to capture both how such resistances are always necessarily partial, firmly rooted in many of the same social logics that shape the categories they seek to escape, and how the rapidly shifting nature of these categories matches the partial mutability of algorithmic categories as used in big data. [50]

Many tactics used by UX professionals are similarly partial, in that they challenge certain norms around their organizations or the product development process, but are often rooted within a broader logic of the role of the market or the usefulness of technology. UX professionals also can shift between multiple roles-as a technical professional, as a values advocate, as a researcher, as a designer- allowing them to make arguments from different positions about what values are important and why.

Metcalf et al. discuss three dominant logics among Silicon Valley ethics owners. First is meritocracy, the idea that hiring "the best people" who want to do the right thing will lead to ethical decision making; second is technological solutionism, that tools like toolkits and checklists, or best practices will lead to an ethical technical solution; third is market fundamentalism, that the ethical solutions worth pursing should add economic value according to the market, and that less profitable approaches are not worth pursuing [43]. Sometimes the resistance practices by UX professionals contest these logics, while at other times they make use of them, suggesting a "soft" form of resistance.

The softness described by Nafus and Sherman is not just about partiality, but also about the softness of material used in resistance. In their case, the process of meaning making with data has "a readiness to evolve what constitutes meaning as it unfolds" [50]. Ethics in the technology industry may be similarly described as being soft, in the sense of having a readiness to evolve what constitutes ethics as it unfolds. Findings in prior work have found that the practice of ethics in the technology industry are not based on formal ethical frameworks or ethical reasoning processes developed in philosophy, but rather an individual's gut feeling of what is right or wrong [26]. While this has been critiqued for its inconsistency, this softness in ethics serves as an entry point for useful contestation regarding how ethics and values should be practiced.

\section{METHODS}

The project utilizes qualitative interviews with UX professionals and observations at meetup events to understand how UX professionals understand their own practices in this space. 


\subsection{Positionality}

I am a design researcher who uses qualitative and design methods in my research and work at an academic institution in Northern California, with geographic proximity to the San Francisco Bay Area and Silicon Valley. The institution is connected to the technology industry by training students and practitioners who go on to work in the technology industry, and by conducting research in collaboration with industry partners. These proximities allowed me to access multiple entry points [9] into the networks encompassing UX professionals, such as by being able to attend local events and recruit interviewees. My expertise and familiarity with human computer interaction and UX practices as a researcher helped me navigate UX and design meetups, providing me a commonality which could serve as an entry point into talking with people in the community.

\subsection{Research Context}

This research was conducted in and from the San Francisco Bay Area in the United States between 2018-2020. During this time, numerous cultural events related to social values, ethics, and technology companies took place. Various controversies, events, and pieces of media were referred to by interviewees and at events observed in this research. These shared cultural touchstones spanned a range of social values issues, and suggested a desire for changes in how technology companies should address or be responsible for social values.

New concerns about personal data were raised through public controversies such as the Cambridge Analytica data-sharing scandal. New pieces of popular media depicted concerns about the potential harms of technology, such as the popular speculative fiction anthology television show Black Mirror depicting stories of negative societal outcomes using near-future technologies. New data protection laws were enacted: The E.U.'s General Data Protection Regulation (GDPR) came into effect in May 2018, and the California Consumer Privacy Act (CCPA) was passed in 2018 and came into effect in 2020. These laws created new responsibilities for companies collecting and processing data, forcing them to comply with new privacy-related statutes.

Some technology companies began taking actions responding to the potential and actual harms perpetuated by their platforms and products. In 2017, several technology companies providing services such as web hosting or content delivery networks began taking steps towards banning white supremacist and hate groups from their services. ${ }^{5}$ A range of large companies introduced new ethics initiatives and tools around artificial intelligence and machine learning systems (e.g., $[8,24,45])$ and began making public commitments to consider social values in the development and use of their products.

At the same time, workers at some of the largest technology companies in the U.S. started engaging in forms of collective action or protest against their employers' practices, using letterwriting campaigns or walkouts to contest certain technology service contracts with clients or internal diversity and inclusion shortcomings.

Altogether, this context illustrates a broad range of actors attempting to address social values issues related to technology. Sometimes the impetus to address values came from external public pressure and regulation, other times from internal worker-led efforts, and other times from corporate-led efforts. The types of values problems varied as well: sometimes it was about how a product is used (and who uses it), other times it was about long-term business relationships and contracts with clients, and other times it was about the conditions of the technology company workplace. Against this varied backdrop, this paper investigates the practices of UX professionals who explicitly think about how social values are implicated in their work, and the tactics they use to try to create change within their organizations.

\footnotetext{
${ }^{5}$ https://www.theverge.com/2017/8/17/16163960/hate-groups-banned-godaddy-cloudflare-facebook-squarespace
} 


\subsection{Data Collection}

Data collection involved conducting semi-structured interviews with UX professionals, and conducting observations at public meetup events where technologists met to discuss topics related to technology design, values, and ethics.

For interviews, I conducted purposive sampling, recruiting people who self-identified as UX professionals who work at large technology companies and who saw themselves as interested in or already engaging in values work. I am interested in practices related to values that occur outside legal compliance processes, thus I excluded interviewees from highly regulated industries in the U.S. where legal compliance processes might dominate (excluding companies whose main products are subject to consumer finance protection laws, health data privacy laws, or educational privacy laws). I also bounded my inquiry by recruiting UX professionals who work at established (beyond the startup phase) companies, as these present a more mature organizational context that may be more likely to have UX teams. I recruited people in several ways, initially asking for referrals from people in my own professional network, and talking to people I had seen attend events related to design and values issues. Based on early interviews where several interviewees described using Twitter as a source to learn about values issues, I also posted several tweets recruiting UX professionals who fit the criteria. While I was physically located in the San Francisco Bay area when conducting this research, several interviewees lived in other parts of North America and were interviewed remotely, since interviewees' professional networks (and many technology companies' employees) are geographically distributed. In this sense, my field site is centered in the San Francisco Bay Area, but also encompasses a social and professional network of workers that expands beyond those geographical boundaries [9].

Interviews took place between Summer 2018 and Summer 2019. Conversations were not scoped around particular values, rather I allowed interviewees to discuss what they considered as being important or relevant to addressing the social implications of their work. Sometimes this led to discussion of specific social values such as privacy, accessibility, or fairness. Other times, values were discussed as a more complex and entangled set of politics, such as ensuring diversity and inclusion within their companies, or supporting the well-being of end users of enterprise systems. At other times, values concerned a set of politics about reducing potential harms to stakeholders that were caused directly or indirectly by technology products.

I conducted interviews either in person or via Zoom video conferencing. Interviews generally lasted between 60-90 minutes. At the end of interviews, I collected demographic information from interviewees. With interviewees' permission, interviews were audio recorded and transcribed. Some interviewees asked that I not record and take handwritten notes instead. Interviewees were not paid, and the study was approved by UC Berkeley's Institutional Review Board. Recruitment stopped at a point of saturation, where the practices and challenges discussed by interviewees began to match the experiences described by other interviewees and by those at meetup events However, it is possible that there are additional practices, challenges, and experiences not captured by the diversity of this interview sample.

In addition to interviews, I conducted participant observation at publicly accessible meetup events attended by design and UX professionals in the San Francisco Bay Area between Spring 2018 and Winter 2020. These meetup events were centered on design, technology, and social values or ethics. Meetups usually included a series or panel of speakers, some time for discussion or Q\&A, and then time for networking with other attendees. Meetups tended to take place on weekday evenings for several hours, generally hosted in downtown San Francisco, usually in office space provided by a technology company or technology-related organization. Some events were specifically targeted 
Table 1. Overall Demographics and Background of 12 Interviewees

\begin{tabular}{|c|c|c|c|}
\hline Role or Job Titles & Genders & Locations & Organization’s Main Products \\
\hline “Designer” (5) & Female (8) & San Francisco Bay & Enterprise/B2B software (6) \\
\hline “Researcher” (3) & Male (3) & Area/Silicon Valley (8) & (Direct to consumer) Educa- \\
\hline Accessibility engi- & Non-Binary & New York City (2) & tional technology (2) \\
\hline neering (1) & & San Antonio, Texas (1) & Social media platform (1) \\
\hline $\begin{array}{l}\text { Product manager } \\
\text { (1) }\end{array}$ & & Toronto, Canada (1) & $\begin{array}{l}\text { Web browser (1) } \\
\text { Independent consultant (1) }\end{array}$ \\
\hline $\begin{array}{l}\text { UX research consul- } \\
\operatorname{tant}(1)\end{array}$ & & & UX meetup organizer (1) \\
\hline $\begin{array}{l}\text { UX meetup orga- } \\
\text { nizer (1) }\end{array}$ & & & \\
\hline
\end{tabular}

towards UX and design professionals, while some were more broadly advertised and attracted people from a range of technology-related jobs.

\subsection{Data Overview}

I conducted interviews with 12 UX professionals who work at large established technology companies and explicitly view attending to values as a part of their work. ${ }^{6}$ Of the 12 interviewees: 5 work in the role of "designer", 3 work in the role of "researcher", 1 has the title of accessibility engineer; 1 is now a product manager but was previously a designer at the same organization; 1 is a UX research consultant who previously worked at a large organization; and 1 is the organizer of a UX meetup. The interviewees' ages range from twenty-six to fifty-two, although most were in their thirties. The diversity of the interviewees' genders, locations, and types of organizations or products are reported in Table 1.

To provide some organizational context, for the 10 interviewees working at organizations (not including the independent consultant and the UX meetup organizer), all the organizations that they work for have matured beyond the startup phase, the youngest organization represented being nine years old. These 10 interviewees worked at their current organization from as little as eight months to as much as seven years. Most (7) have worked at their current organization between one and four years.

Interviewees also had a range of lengths of experience working in the technology industry at large: 3 had ten or more years of experience, while 9 had two to nine years of experience. Some interviewees drew on their past experiences as well as their current job during our conversations.

I attended 12 meetup events related to values, ethics, and technology design in the San Francisco Bay Area to conduct participant observation. They included 6 events aimed at UX professionals and 6 events aimed at technology professionals interested in privacy. At these meetups I took pictures (when allowed), and took jottings while listening to panelists and speakers, particularly paying attention to how panelists and speakers would frame their discussion of values issues, and any strategies or practices that they mentioned.

\footnotetext{
${ }^{6}$ Characteristics of the interviewees are reported holistically across the group, rather than describing each individual interviewee, to respect participants' wishes regarding anonymity and re-identifiability. Pseudonyms are used when referring to individual interviewees. When relevant, specific characteristics of interviewees are presented in context when their quotations or accounts are reported on.
} 


\subsection{Data Analysis}

Analysis included multiple rounds of inductive coding and theoretically-informed coding, following an abductive analysis framework [65]. In a first round of inductive coding, codes were written directly on documents containing interview transcripts, field notes, and jottings from observations. This included using descriptive coding to note and identify topics present in the data [58, pg.88], and process coding to note and identify practices and actions in the data [58, pg.96].

Qualitative coding software Atlas.ti was used for a second round of coding. New inductive codes were created corresponding to categories and themes that emerged from the first cycle of coding. These included whether an action was a technical practice, a social practice done by a UX professional, or an organizational practice done by an organization. Theoretically-informed codes were used to identify concepts discussed in prior work, including "values levers" (practices that make values visible for technical action) [61], and practices of values advocacy [60]. Throughout the data analysis process, I wrote theoretical memos [39, pg.210], short analytical documents exploring early observed themes in the data, expanding on themes represented by some of the codes, or to summarize similarities and differences between interviewees' perspectives.

\subsection{Challenges and Limitations}

One challenge in conducting this research is that it takes place against a backdrop of a culture of secrecy among technology companies. This may be due to companies having policies in place to guard against corporate espionage, a desire to maintain a competitive advantage using proprietary information, or wariness of having negative press coverage about their products. Nevertheless, this culture was visible in the research, such as having to check-in with an assigned escort and sign non-disclosure agreements in order to enter technology company offices where some meetup events were held. These dynamics also prevented direct observation of UX professionals' daily practices at large companies. However, interviews provide an opportunity to talk to people who have reflected on their practices and strategies, and on what these practices mean to them. Conducting individual interviews outside of the workplace also provides interviewees with more freedom to discuss things that they may not feel comfortable discussing in workplace settings, such as expressing frustrations or discussing the emotional aspects of their work.

Nevertheless, my findings are limited by people who were willing or able to talk to me, as well as by what they were willing to share. Interviewees would sometimes self-censor their descriptions of their experiences to obfuscate product details, some paused at points in the interview to carefully consider their phrasing, while others would sometimes describe experiences in a high level of detail, but then ask that certain details not be shared, which I have respected. These instances potentially reflect a fear of professional retaliation, given that vocal activist employees have been previously fired by technology companies $[10,44]$.

The findings of this research are also limited to understanding work practices at established or large technology companies among the networks of people interviewed and observed in this study, many of whom (though not all) were located in the San Francisco Bay Area and explicitly see their work as political and values-laden. The values and ethics deemed worth promoting by these particular UX professionals, and their practices of promoting values, may not necessarily generalize to other positionalities and cultural contexts [1,4,47]. Furthermore, UX practices at different types or sizes of companies, such as a startup or small design firm, may differ. The findings of this research are also situated within U.S. corporate work culture-for instance, U.S. technology workers were almost all non-unionized at the time of data collection, and social benefits like healthcare are largely tied to employment in the U.S. context. The workplace power dynamics that influence some of the tactics reported on in this paper may differ in other cultural and geographic sites. The 
findings of this research are meant to begin to explore the space of the tactics of UX professionals when surfacing values-related issues within these particular situated contexts, rather than be an exhaustive description of all UX professionals' practices.

The following sections present findings from the research. Section 4 introduces practices and tactics of soft resistance relating to three categories of change. Section 5 reports on how these three forms of change are sometimes successful, and sometimes not. This leads to experiences of tension among the interviewed UX professionals, between hope that these practices and tactics will lead to meaningful change, and skepticism that they will not work or be ineffective.

\section{TACTICS OF SOFT RESISTANCE IN VALUES WORK}

The UX professionals who I interviewed and observed utilize a broad range of practices in the name of addressing values. In this section, I describe how these UX professionals work towards: (1) making more space for UX professionals to conduct values work; (2) making values visible and relevant to others in the organization; and (3) changing organizational processes and orientations towards values. Each form of change makes use of different tactics. While I describe these three categories separately for analytical clarity, all three simultaneously exist and sometimes overlap. The values that the participants report promoting vary, including promoting end-user well-being, preventing harm to end-users, promoting diversity and inclusion among users, gender equality, accessibility, and privacy.

I refer to practices that seek to create change or resist as "tactics," using de Certeau's description of tactics as tools of those who must operate in spaces that they did not create and do not control, as compared to strategies which are tools of institutions and the powerful who can create and manage broad spaces and environments [13, pgs.35-37]. Through the lens of soft resistance, many tactics used by participants to work towards these changes are partial, in that they challenge certain norms around their organizations or the product development process, but are often rooted within broader dominant Silicon Valley logics such as: meritocracy, that people who want to do the right thing will lead to ethical decision making; technological solutionism, that better design will lead to an ethical product; or market fundamentalism, that ethical solutions will increase economic value [43].

\subsection{Creating Space for UX Expertise to Address Values}

One set of tactics focuses on making more space for UX professionals to address values through their work. Within organizations, responsibility for addressing values and ethical issues can be spread across different stakeholders who might approach a values problem with a different set of politics, methods, and tools (e.g., values as a legal compliance problem, values as a public relations problem, or values as a requirements engineering problem). These distributions or handoffs of responsibility may not always include UX in a meaningful way. Participants discuss finding ways to incorporate values into their everyday practices. In doing so, they are not only seeking to design more ethical products, but are also arguing that UX expertise should be included in their company's approach to values.

4.1.1 Broadening Who the "User" is in User Research. A common practice of values work among user researcher participants is resisting organizational assumptions about who users are by promoting diversity in who gets counted as a user in user research. User research is already an accepted practice at technology companies, but participants attempt to tactically expand and diversify the people they include as "users." This serves as a way to surface potential harms that can disproportionately impact different groups of users, and promotes the values of diversity and inclusivity by broadening who gets considered as a user. However, doing this work can take more time and organizational 
resources compared to doing user research with a narrower group of users, such as the most common or most profitable group of users.

In an example of trying to promote this type of diversity, Laura, a UX researcher at an educational software company, discussed trying to expand her interview pool to notice and include people from Indigenous communities in the U.S. While they are a small percentage of potential users, Laura wants to hear from them to make sure they are well-served if they use her company's product. While Laura wanted to include more research subjects from tribal colleges, she faced some pushback from other stakeholders in her organization:

Laura: But when I was talking about it [recruiting users from tribal colleges], even our product marketing person who does think we should help people and care about people, was like "yeah, but we can't make a marketing strategy specifically to them because there's not a large enough population of them to warrant us to spend that money."

I was like [sighs] "Well, way to kill the buzz." [laughs] But it's true because we are a private company. We are not a non-profit dedicated to advancing the education of Indigenous people in this country. Nor should we claim to build a product that's going to end some kind of plight in that community. [...] We should try to figure out what group do they align with the most. Is it rural students? Okay, that then broadens the population, makes the business case a lot more easy to fight for, and also we're not making a claim that we cannot live up to.

Laura is reflexive about the limits of technological solutions in solving problems of inequality, noting that a technology is not going to solve the "plight" of Indigenous people. As a form of soft resistance, Laura tries to find ways to consider the positionalities of Indigenous and tribal communities, even as others in her organization do not see a business argument for doing research and marketing with those communities. Instead of categorizing her work as being about students in tribal communities, Laura considers using the category of rural students instead, to translate her concerns into a business case. It is an imperfect, but tactical, way to try to find a way to support and make space for her values work. Later on, Laura ties her surfacing of ethical issues to making space in the organization for UX expertise to address values and ethics.

Laura: I don't think it would come up if the designers or the UX people or the product people didn't bring it up. It's not something that I have found a leader on [from] the business side: CEOs, CFOs, all those people. Like their job is not always to think about the ethics which is unfortunate. [...] But I think the only way that social implications come up is if you make them come up. [...] I think the only way for it to happen is for us, at least for the team of UX people, to be on the same page to make a united front towards product.

Other user researcher participants also discuss tactically expanding their research pool to include stakeholders in different roles. Particularly at enterprise software companies, product managers might want user research to focus on the needs of their clients, who are often managers at the client organizations. However, several user researchers discussed how they push for talking to end users, who are often the workers at the client organizations.

These efforts to contest the definition of who counts as a user frame UX expertise as central to efforts to prevent harm to often marginalized populations, or to increase diversity in who is considered as a user. But these changes remain partial as the broader category of "user" is held constant. In Laura's case, she wants to avoid causing harm to users coming from Indigenous populations. But in order to do so, this population has to become legible to the company as a potential user group of the system-rural students-around whom a business case can be created. 
Avoiding causing harms to different populations means that these populations have to become legible as potential "users" who can then be designed for. While expanding who counts as a "user" is a tactical resistance practice to try to get companies to consider a broader set of people, these actions enroll new populations into the broader market and technological solutionism logics in the technology industry as potential consumers and users. This framing can be useful towards promoting certain forms of inclusion and diversity, but can also limit consideration of alternate relationships between people and technology [7].

4.1.2 Designing Affordances Subversively. Participants also address values issues by designing particular affordances in technical artifacts, potentially to promote values that may go against their organization's financial interests. Genevieve, a senior product designer at an enterprise software company, considers how she could try to propose or design features in their enterprise software in ways that might promote values related to worker well-being, rather than the employer's needs.

Genevieve: We've been asked to design an out-of-the box dashboard for [...] managers to use to see information about their workers. The usual metrics are: time to completion on a case, amount of time you spend on the phone. There's always a CSAT [customer satisfaction] score. [...] So when we did our [design] explorations of that, we tried to think about not just what are the metrics that the team leader wants to see, because they're reporting up to somebody and it's all about efficiency. But also how are some ways we can use that experience to basically teach them to be less shitty managers. There was one exploration we did around being like "hey, could we use this data to say 'people who are allowed to take a break every so often perform better'?" or that kind of thing.

Later in the interview, Genevieve also discusses a desire to subvert design recommendations to try to include pro-unionization features:

Genevieve: I do think all the time though about what are some features I could pitch to product managers to build that are essentially unionization features. But we could call them something else to try to camouflage and make [them] look like "team collaboration and efficiency" or something.

At the moment, these musings by Genevieve are more speculative than implemented tactics. However, Genevieve postulates tactically repurposing the existing UX process of design explorations, which are meant to explore different potential solutions to a problem. Beyond different technical solutions in the explorations, Genevieve proposes design outcomes that embody alternative proworker and pro-unionization values. This type of exploration suggests a practice similar to critical and speculative design. Genevieve's values-oriented design explorations represent a "values fiction"the use of existing technologies that embody an alternate set of social values [14]. Keri, a lead UX designer at an enterprise software company, discussed a similar experience where colleagues attempted to design worker-friendly language in the interface after a worker completes their tasks, such as a message saying "go grab a cup of coffee," challenging the client's desire to maximize worker efficiency.

This tactic of resistance challenges whose values the company should attend to, with Genevieve and Keri positing that their companies should attend to the values of the workers who have to use their software, rather than the client organizations who purchase the software. Attending to end users' and workers' values via design affordances places UX expertise as central to this endeavor.

At the same time, this tactic of resistance is partial, as it fits within the broader logics of technological solutionism, the idea that a re-configured product will lead to a different, more worker-supportive outcome (potentially obscuring other non-technological forms of political change). 


\subsection{Making Values Visible and Relevant to Others in the Organization}

Tactics that aim to resist, contest, and change the organization also occur beyond UX professionals' everyday design practices. A second set of tactics discussed by participants seeks to get other organizational stakeholders to see values as important and relevant to their work. These tactics attempt to enroll other organizational stakeholders into promoting values in ways that reflect the interviewed UX professionals' perspectives.

4.2.1 Making Values Visible Rhetorically to Other Organizational Stakeholders. Participants' tactics include making values issues visible in conversations and meetings with other organizational stakeholders whose focus is on metrics. UX professionals generally do not have final decisionmaking power over product decisions, and thus need to tactically translate and legitimize their values concerns to decision-makers such as product managers. Britney, a user researcher at an enterprise software company, discusses her attempts to frame a concern about protecting end user well-being (the workers of client organizations who buy software from Britney's company) using business terms, making the issue visible as a financial or reputational risk:

Britney: I care about those end users being able to do their jobs and do their jobs well, and support their families, and also not have a horrible time using our product while they're doing it. [...] They don't have a choice [to use this product]. [...]

But that reasoning isn't gonna motivate product managers. So a lot of the argumentation that I do is around, "if we do this, we've already seen that we may get some negative feedback and even negative press, negative social media, on this small scale. If we roll this out more widely, it's a risk that we're going to get a lot more negative feedback. And what that means is that we're losing trust with these companies. Trust has always been our number-one value [...]. This is a significant reputational harm or reputational risk."

Britney's concern is about the end users' wellbeing. However, instead of framing her concerns in terms of potential harms for the worker end users, Britney frames it as a reputational risk for her organization and draws on her company's corporate value of "trust", in order to make the issue visible to product managers. At the same time, this tactic makes use of market fundamentalism logic: Britney's rhetoric suggests that not addressing this potential harm is a reputational and financial risk; addressing the potential harm is thus the better market strategy.

Similarly, Laura, a senior user experience researcher at an EdTech company notes that usercentered justifications do not always make issues visible in ways that lead to action, but financial arguments can.

Laura: We can't necessarily say "this is good for the user." That answer only lasts so long, it only works so much. But then when you have that opportunity where [...] you say it's making you lose money, then [the product team] they're like "okay, now let's talk. Now we'll have this discussion." And so it's tying it back to the revenue dollars.

Laura makes potential harms and benefits to the user visible in conversations with product teams by utilizing market logics in her argumentation. This is necessary in part because her company's product team, not the UX team, makes final decisions about the product.

This rhetorical tactic of using financial and reputational language to justify arguments works towards re-shaping organizational priorities and goals in product development in ways that align with the values that these UX professionals wish to promote. This tactic makes values visible and relevant to other organizational stakeholders, but utilizes existing market logics to do so. This 
tactic is partial and potentially limited because not all social values can be easily translated into the language of risk and financial loss.

4.2.2 Expanding On and Subverting Design Resources for Others. Participants discussed creating design resources for others to help promote their perspectives on values throughout the organization. These tactics often expand on or subvert existing UX design practices that are viewed as legitimate everyday practices. Cecilia, a user researcher at an enterprise software company, discussed the existing use of personas, particularly a set of accessibility personas developed by Microsoft that provide a spectrum of different types of ability [46]. In a side project, she and teammates tried to come up with a similar set of personas that might help others think about workers with different amounts of power in the workplace. The project was ultimately unsuccessful due to shifting organizational needs. As a "side project," it did not get finished when her UX team was needed to work on other organizational priorities and projects. Nevertheless, this tactic tried to repurpose personas, an existing UX practice that is seen as legitimate to others, to try to drive more attention towards an issue Cecilia and her colleagues wished to promote: the power dynamics and spectrum of conditions for laborers.

Similarly Genevieve, a senior product designer at an enterprise software company, uses personas to foreground the value of accessibility, utilizing the toolkit from Microsoft.

Genevieve: [Microsoft's accessibility toolkit] is basically a matrix of people with a variety of kinds of disabilities: Temporary, situational, and permanent. So you could have a temporary physical disability if you sprained your wrist. And the same things that are going to benefit someone who is an amputee are going to benefit somebody who can't use their arm temporarily because they sprained it or they're holding a baby or something. It's this idea of when you design for maximum inclusivity, you actually create a better experience for everybody. And disabilities aren't permanent, we can kind of move throughout them. So I did a version of those using [MY COMPANY]'s personas. Like a temporarily disabled [customer service] agent, and a permanent, and a situational, as a way of trying to educate customers on accessibility.

Genevieve takes the personas that her company already uses to think about service workers, and explicitly adds in new dimensions to show a spectrum of ability, as a way to promote thinking about accessibility among those in her organization and the client organizations who interact with the personas.

These attempts to center thinking about values and their diversity using personas expand conceptions of who "users" are by adapting, expanding, and subverting design tools that are already viewed as legitimate. This helps UX professionals work towards organizational cultural change by promoting their perspectives on users and values amongst others in the organization. At the same time, this tactic does not question the category of "user" itself; the tactic still envisions a relationship between a commercial product and its user.

\subsection{Changing Organizational Processes and Orientations Towards Values}

A third set of tactics involves participants attempting to change and shape the processes and politics of the organizations they work for. These tactics attempt to re-configure how their organizations conceptualize, address, or respond to values.

4.3.1 Making Values Visible and Legible Through Organizational Metrics. The interviewed UX professionals use this tactic to make the values they care about and their labor visible to their 
companies. Tying values to organizational metrics can provide legitimacy and legibility. ${ }^{7}$ Work within technology companies is often organized around performance metrics such as Objectives and Key Results (OKRs), or Key Performance Indicators (KPIs). Sometimes these are seen as barriers to doing values work, because existing metrics may not be related to users' experiences or social values issues, but instead focus on a system's technical or financial performance.

In contrast, Nova's experience with organizational metrics suggests potential opportunities for forms of tactical engagement. Nova works as a senior designer at an enterprise software company. In recounting a team meeting, Nova brings up the idea of utilizing the rhetorical power of OKRs to help promote the values of diversity and inclusion in how their products get used.

Nova: So we were making recommendations and one of those recommendations was to explicitly include cultural outcomes as part of the OKRs, because my [product] org [...] is trying to be much more OKR focused. [...]. There's no metrics around workplace culture and how it looks. And they [the product organization] seemed really receptive to making that an explicit objective with key results that you could put under it. So that was cool.

Similarly, at a user research meetup event, attendees discussed how work at their organizations is organized around OKRs. One attendee suggested that they need to find ways to "be in the room" when decisions are being made about how to define the OKRs and other metrics. What was left unstated in this conversation was the lack of compensation, energy and time costs incurred, and emotional labor required to be the individual in the room doing this work.

Several participants discussed other measurement tactics they use to increase the legibility of values issues among others in their organization. Laura, a senior UX researcher at a consumer EdTech company, discusses creating an ethical debt tracker by logging social issues in Jira, product management software that allows tracking of bugs.

Laura: What did we find out that we didn't actually take action on? [...] I've done these things in the past where we keep a backlog in Jira of things we know are really important. And we bring it up over and over and over again. My manager, the manager of the UX research, team really liked that idea.

Laura's intervention seems to be successful at getting buy-in from her manager. Other interviewees similarly discussed the potential of using bug tracking software in their organization to try to capture attention for social and ethical issues.

These tactical engagements with measurement and bug tracking provide contestation over what should count as an "objective and key result" or what should count as a "bug." This tactic expands these established organizational metrics to include consideration of values and ethical issues. This tactic may help shift organizational politics and strategies around values by subtly re-orienting work priorities. At the same time, it potentially places values and ethics into logics of measurement-they become things that can be "measurably" improved, quantified, optimized, and accomplished. These practices are similar to Nafus and Sherman's discussions of "soft resistance" in the Quantified Self community, where people critically engage with measurement practices (while not dismantling measurement altogether), opening up new spaces for alternate forms of knowledge production

\footnotetext{
${ }^{7}$ I use the word "legibility" building on Scott's use of the term [59]. He describes legibility as a problem of the premodern nation-state, which was "partially blind" to knowing about the activities and local social practices of its subjects (e.g., local land use practices) - which are described as illegible. Through metrics, standardized weights and measures, systems of private property ownership, population censuses, and similar measures, information becomes simplified and legible to the state, so that social practices can be recorded and monitored [59, pg.2]. However, these metrics never fully account for all local social practices. In my use of legibility, I consider how companies and organizations make their workers' activity and practices visible in ways that can be recorded and monitored through metrics. These metrics may not fully capture the work done by UX professionals to address values.
} 
through measurement [50]. Furthermore, workers' tactical engagement with forms of managerial measurement and metrics are not fully new practices: Khovanskaya et al. discuss how mid-20th century worker unions resisted and contested managerial-defined metrics and data collection by engaging in tactical and alternative forms of data collection about their own work practices [33, 34]

4.3.2 Using Organizational Values to Create Spaces for New Forms of Values Work. Another tactic utilized by participants to change organizational politics and strategies is to tie their values work to corporate values and mission statements. In doing so, they carve out a space to conduct values work in a way that allows them to bring their perspectives and expertise on values issues to the forefront Appeals to corporate values can also help build alliances and coalitions with other organizational stakeholders. Furthermore, this tactic allows the interviewed UX professionals to re-interpret and re-instantiate corporate values and mission statements in ways that align with the values they wish to promote.

For example Britney, a user researcher, describes using her company's corporate value of equality as a lever to bring social justice topics into work conversations. Yet, she notes that this requires "negotiation of what those values means and how they should be interpreted" - others in the organization do not necessarily see the same connection between the corporate value and issues of social justice.

Nova, who works at an enterprise software company, discusses how their organization has tried to include diversity and inclusion factors into worker evaluations and product processes by treating it "like a product."

Nova: There's been this huge push for diversity and inclusivity. And there's a lot going on internally around that. On our internal review, there's actually a section at the top to talk about how you've been promoting the inclusive principles [...] And we're supposed to be treating it like a product. Like a product that we can deliver on. Which I have qualms about. But also I'm like "ok, this is a thing we're doing, and I think it's important we're doing that."

While Nova feels qualms about treating diversity and inclusion "like a product," Nova also discusses how it has created space and given them the license to do values work. Beyond their formal UX work, Nova engages in a broad range of workplace activities around diversity and inclusion. This includes holding gender education events in the organization, helping advocate for gender neutral bathrooms at the workplace, talking with others about workplace grievances, meeting with other workers in the organization who volunteer for diversity and inclusion initiatives, talking about diversity and inclusion and LGBT resources at internal organizational meetings and at customer-facing conferences and trade shows. Nova ties their ability to conduct these broad range of actions to the company's broad and publicly stated commitments to diversity and inclusion.

Nova: Because [The CEO] and [COMPANY] more broadly have had this diversity and inclusion focus, and being like "this should be at the core of everything we do," I feel it's given me a lot of leeway to be able to be like "I'm acting in line with company principles."

This suggests an interesting tension. The organization's framing of diversity and inclusion "like a product" can obscure the social and political work necessary to advance those goals. At the same time, framing diversity and inclusion "like a product" gives the work being done towards addressing these values greater visibility and legitimacy, and provides license to workers to engage in a wide variety of practices. This license allows Nova to simultaneously engage in practices that push the values of diversity and inclusion in directions that their company might not have imagined them 
Table 2. Summary of Soft Resistance Tactics Described by Interviewed UX Professionals

\begin{tabular}{|c|c|}
\hline Type of change sought & Tactics \\
\hline $\begin{array}{l}\text { Creating space for UX exper- } \\
\text { tise to address values }\end{array}$ & $\begin{array}{l}\text { - Broadening who the "user" is in user research } \\
\text { - Designing affordances subversively }\end{array}$ \\
\hline $\begin{array}{l}\text { Making values visible and rel- } \\
\text { evant to others in the organi- } \\
\text { zation }\end{array}$ & $\begin{array}{l}\text { - Making values visible rhetorically to other organizational } \\
\text { stakeholders } \\
\text { - Expanding on and subverting design resources for others }\end{array}$ \\
\hline $\begin{array}{l}\text { Changing organizational pro- } \\
\text { cesses and orientations to- } \\
\text { wards values }\end{array}$ & $\begin{array}{l}\text { - Making values visible through organizational metrics } \\
\text { - Using organizational values to create spaces for new forms } \\
\text { of values work }\end{array}$ \\
\hline
\end{tabular}

doing, while also presenting themselves as working in accordance with the company's goals, due to the principles' legibility and legitimacy within the organization.

Other participants similarly reported on critically questioning and expanding what practices could be conducted under corporate values and principles like "equality" or "diversity and inclusion." Corporate values and principles create a space within which values advocates like Britney or Nova can contest and bring new interpretations to their companies' values and principles. Furthermore, tactical engagement with corporate values can help these UX professionals accrue power in the organization by rhetorically aligning their work with their organization's stated goals. By instantiating corporate values in ways potentially different than how the corporation views those values, the interviewed UX professionals try to re-configure the organization's politics and strategies to better align with the social values they wish to promote.

At the same time, tactical engagement with these principles means that not all aspects of the corporation's perspectives are contested. Nova's organization wants to treat diversity and inclusion "like a product," suggesting that diversity and inclusion should take place within the logics of technical solutionism and market fundamentalism. Nova is not fully comfortable with this, but nevertheless sees the stated commitment by their parent organization as providing leeway and an opportunistic space to take action.

\section{TENSIONS OF SKEPTICISM \& HOPE, AND SUCCESSES \& FAILURES, IN TACTICS OF SOFT RESISTANCE}

The previous section described tactics of soft resistance used by the interviewed UX professionals while engaging in values work (summarized in Table 2). This section reports on findings related to participants' expressions of hope and skepticism: hope that the tactics discussed above will lead to change, and skepticism about whether they will lead to meaningful change with regard to values. Sometimes their tactics lead to successful changes; other times they do not. These tensions are indicative of the partialness of these tactics.

The tactics reported by interviewees and discussed at UX meetups represent attempts to change technology organizations from positions within-and often from "below," given that they are frontline workers (rather than managers or executives) and that UX work is not always given the same prestige or legitimacy as other forms of technical work. Their tactical engagement with their companies reflects that UX professionals are generally not in a position to contest or resist all aspects of their organizations. One senior UX researcher described this in terms of picking their battles, saying "the hills you die on are the big ones." 


\subsection{Skepticism and Hope in Creating Space for UX Expertise}

Addressing values problems through UX expertise faces limitations when other stakeholders disagree that there is a values problem in the first place. Keri, a lead UX designer at an enterprise software company, discusses how a colleague's desire to design an interface to promote worker well-being faced pushback by a client whose managers used the software. This concerned the messages displayed in "empty state" of the system, when workers finished a set of tasks assigned to them.

Keri: I had heard from someone else, that there was an effort a while ago to make empty states in [PRODUCT] more friendly. And so they created a bunch of different variations of that empty state. Like a sort of friendly illustration with some message under it. And one was a coffee cup and the message was "hey, you're all done with your tasks today, go grab a cup of coffee." And they actually got a complaint back from [CLIENT ORGANIZATION] where some executive saw it and was like "I do not want people to be going and getting cups of coffee." So that was an example of where the message to the end user didn't resonate well with the person who was their manager and is buying the product.

This attempt at using the "designing affordances subversively" tactic did not succeed. While interviewees expressed hope that UX professionals can introduce design elements that promote worker well-being, there is skepticism about whether these proposals will be enacted, as the decision-makers who purchase the product have different interests.

Alternatively, participants noted that if they are unable to create change within a particular company, they may decide to take their expertise elsewhere. But tensions between hope and skepticism also arise in participants' choice of workplace. Henry, a lead UX designer at an educational technology company, reflects on having the power to choose where to work. He had a bad experience working at a prior company which he now reflects on as "misguided" due to the financial harms faced by some of that company's users. Yet at the same time, he is aware that choosing to continue working in the technology industry could still potentially cause harm to others.

Henry: I think one of the most important ethical calls that you can make as a designer is where to work. After a lot of bouncing around I finally ended up in EdTech. It's not perfect, but it is-I think anyway-probably one of the less harmful places to work in consumer technology in the Bay Area. And you know it says something that you have to lower the bar to "less harmful" rather than "helpful" [laughs and sighs].

Participants face individual decisions about what companies to work for. Henry provides a partially hopeful account, seeing the decision of where to work as an important ethical decision for individual UX professionals. But more skeptically, leaving a company or project does not always solve the broader values problem, as companies can generally hire someone else who is willing to do the work. Other interviewees expressed concerns that if co-workers engaging in tactics of resistance leave the company for other jobs, then there might not be anyone left within the company to push back against management's or product teams' decisions. This suggests limitations in locating responsibility for change in individual technology professionals.

\subsection{Skepticism and Hope in Making Values Visible to Others Organizational Stakeholders}

Participants express tensions between hope and skepticism in their ability to make values visible and relevant to other organizational stakeholders. Some interviewees describe moments of success, such as Nova seeing some changes based on their diversity and inclusion advocacy work: 
Nova: I get a lot of positive feedback about how I've changed folks' view on gender. I openly use they/them pronouns in the office which I guess you could see as political. It definitely feels more normal now, but it is political and was political especially when I started using it. [...] I advise on a lot of trans-related [conversations about] "oh we're thinking of doing this feature." I end up getting looped into the conversation and providing perspective. It's weird to have other product teams who give a shit about that sometimes.

But at other points in our interview, Nova also describes frustrations at needing to bring up consideration of diversity repeatedly in meetings with co-workers.

Nova: I'm gonna keep repeating [...] "we should be considering this in our use cases" and continue saying the same shit nobody's listening to. But like it's at least part of the background noise of like "oh yeah I have heard this before." So it feels like a futile action, but like a necessary one.

Nova wrestles with the energy and exhaustion it takes to constantly be the person advocating for and surfacing values issues. The ongoing and often repetitive nature of this aspect of values work can compound emotional frustrations and lead to mental exhaustion over time.

Others describe tensions about whether or not their interventions with other organizational stakeholders lead to the desired changes. Throughout our conversation, Cecilia, a user researcher at an enterprise software company, discussed how she would bring up values issues regarding various products with other organizational stakeholders, but she also worried about whether or not she went far enough in trying to address these concerns. Through several excerpts of our conversation, Cecilia discusses a piece of business software that would allow employers to track the GPS locations of employees, and her concerns that employees would not have autonomy or choices about sharing that data with their employers.

Cecilia: When I started my job, I did feel more nervous to even raise any of this stuff. Like I remember the first time that I raised, "are we automating people out of work?", it felt like a little bit risky to bring that up.

Cecilia: With the GPS, I guess I was sort of hoping, "Oh, if I keep bringing this up, it will be on people's minds and maybe it will push things in a certain direction." Even right now talking about it, I'm like, well maybe I should have tried harder to push. I had some thoughts about it. Can we tell people that their tracking is on so they know, or can we have it default to a less granular setting? But I didn't push for those things or make them formal recommendations.

Cecilia: I think raising the conversation with more people and having more people be thinking about it and being forced to navigate the tension of these things-it feels that's helpful. Cause then it at least raises the conversation as opposed to it just getting completely glossed over or just not even being a thing.

Cecilia raises a distinction between surfacing values issues and addressing them. At the same time, she mentions how surfacing these conversations in the first place can feel professionally risky, as it is not clear how far she can go in advocating for these changes before facing professional repercussions. Cecilia is conflicted about whether or not she could have done more to try to push for changes in the GPS system among her co-workers to address privacy and autonomy concerns. Yet she is still hopeful that having conversations and surfacing values issues with others in the organization can lead to change over longer periods of time. 


\subsection{Skepticism and Hope in Changing Organizational Processes and Orientations}

Many participants acknowledged that they face struggles because their companies are focused on selling products, rather than asking whether the product promotes certain social values or has negative ethical effects. Given this recognition, participants expressed mixed feelings about various corporate initiatives related to social values and ethics.

Values and ethics in this context can be considered "soft," meaning that their conceptualizations can evolve and are open to interpretation and contestation. Thus, UX professionals can tactically interpret and instantiate corporate values in new ways. However, it also means that their companies can instantiate values and ethics initiatives in ways that are in tension with the participants' worldviews. While Section 4.3.2 describes how some participants leverage corporate values statements to legitimize their values work, others are more skeptical of corporate values and ethics initiatives, seeing them as public relations or ethics washing overtures. Genevieve describes displeasure with an executive at her enterprise software company who is in charge of issues surrounding equality and diversity. She describes a presentation made by this executive at an industry conference:

Genevieve: He did a product demo of some technology that [CLIENT] had wanted [...] Shortly after that, I found out that [CLIENT]'s workers were on strike over that exact technology. And not only did we not say anything about that during the keynote, but the messaging was very much around "equality" and "putting the customer first" and "empowering [CLIENT]'s workers" and how good [CLIENT] was to their workers. It was just this really obvious, gross, union bashing, PR stunt that felt really awful to be part of. And again that's powered in part by the products that I worked on.

Efforts at organizational change can also be fragile and not necessarily lead to long-lasting change, as reflected by Jerry's experience with his social media company's community health team. A community health team was created to address issues like racial bias that were occurring on the platform, but he noted that it relied on volunteer work, and that the resources it garnered was in part dependent on how the company leadership viewed the team.

Jerry: For a while we had essentially three people on staff [assigned] to this, just general issues around community health. Initially they were specifically working on racial profiling, but it was a product manager and a designer and a copywriter. And then we would find engineering resources here and there to help them build things. But that was the staffing for a while. And then that kind of got dissolved a little bit once the company kind of shook up a little from the leadership changeover.

The effects and impact of UX professionals' values work and attempts at change can be enabled or disabled by key organizational decision-makers. In Jerry's experience, he saw potential organizational changes that could help address ethical harms related to his company's products, but new leaders at his organization decided to take different paths.

\section{DISCUSSION}

The tactics of soft resistance conducted by the interviewed UX professionals encompass more than trying to incorporate consideration of values into their research and design practices. They also attempt to create forms of organizational change. In doing so, these UX professionals try to resist and change some of the dominant narratives and structures in their work, while also tactically engaging and using dominant logics to try to achieve the changes they seek. In this section, I reflect on (1) the affective experience of engaging in soft resistance; (2) how the lens of soft resistance draws attention to tactics of resistance within UX professionals' values work; and (3) implications for values in design research and practice. 


\subsection{The Affect of Soft Resistance}

When talking to UX professionals, their description of their experiences included discussion of strong emotional components, such as discussing feelings of frustration at challenges and failures, while still needing to manage and regulate their emotions in order to maintain professional and social relations. Adding to feelings of frustration, many of the practices discussed by participants were viewed as extra or additional to normal work tasks, limiting the visibility of their work.

Trying to convince other organizational stakeholders that values are important often requires the emotional labor of performing "niceness" [29, pg.167] when surfacing these issues, even when UX professionals are tired and frustrated of repeatedly voicing concerns. This emotional labor emerges in the maintenance of social relationships with other organizational stakeholders, such as product teams, managers, and executives. In addition, having to repeatedly voice and legitimize concerns can also lead to exhaustion and fatigue. This draws parallels to Ahmed's research on the politics of complaint [2]. In part, Ahmed argues that speaking up to ask for changes can be labelled by listeners as complaint and dismissed, as listeners focus their attention on the speaker as problematic, rather than attending to the problems the speaker describes [2]. Furthermore, the work of contestation and enacting change from within involves navigating between feelings of skepticism and hope, recognizing both the potential for change as well as the limits of change, often simultaneously. The affective experience of UX professionals seeking to enact change parallels $\mathrm{Su}$ et al.'s discussion of the affective experiences of technology workers who engage in critique [64], perhaps suggesting that critical UX professionals may be able to find allies among other critical tech workers.

While this interview sample is not necessarily representative of all UX professionals who explicitly conduct values work, it is worth noting that 9 out of 12 were female or nonbinary, suggesting that (like other forms of emotional labor) the emotional labor of values work disproportionately falls on female and non-male technology professionals to conduct.

\subsection{Soft Resistance as an Analytical Lens}

The analytical lens of soft resistance provides a way to more carefully to consider the double bind of attempting critique, contestation, and change from within companies: a worker's resistance actions may be seen as too radical within an organization, but not seen as going far enough from an external observer's viewpoint. Researchers have criticized corporate discourses around technology ethics and values that utilize a technological determinist logic [27] and serve to "reproduce, rather than subvert the legitimating power of dominant actors." [30] The lens of soft resistance can help researchers acknowledge the dominant power that technology companies play in setting discourses around values and ethics, while also recognizing the actions of critique, contestation, and resistance enacted by workers within those companies.

Viewing the tactics in Section 4 as a form of soft resistance helps recognizes practices of contestation and critique from frontline positions within and "below" companies that might otherwise be overlooked. Lindtner et al. describe these as "subjectivities of intervention that do not fall into these more familiar frames of what counts as technological counterculture" [38, pg.16]. Indeed, the interviewed UX professionals' tactics of soft resistance utilize some of the very logics and cultures that they are simultaneously contesting and critiquing. For example, they report contesting and providing alternative definitions of: who counts as users; of corporate principles like "equality" and "diversity and inclusion"; and of metrics like Objectives and Key Results (OKRs). At the same time, the arguments that UX professionals deploy may make use of the dominant logics of market fundamentalism and technological solutionism. This reflects the partiality of soft resistance in 
values work. While these tactics can succeed in creating some changes, there is also not a way to fully escape or transform the institutional and economic forces working against them.

This partiality is not done because of willful ignorance or lack of recognition of these logics. Indeed, several interviewees feel ambivalent about engaging in these logics. However, to get traction and visibility, soft resistance tactics can help create a toehold to begin re-configuring organizations to promote the values and ethics that these UX professionals care about.

Furthermore, "soft resistance" does not equate with ineffective practices. As Nafus and Sherman write, "softness' in soft resistance is not ineffectiveness but a powerful mutability capable of calling into question who gets to do the aggregation and how. [...] We have suggested too that the 'resistance' in soft resistance is not just rejection but has its own productive potential" [50]. There is sometimes a presumed "softness" in technology companies' practices related to ethics, due to the lack of adoption of formal ethical reasoning or use of philosophical ethical frameworks in decision making However, this mutability and malleability of the meaning of "ethics" allows for a broad range of tactical moves by UX professionals to engage in values work. Sometimes this involves making financial and business-oriented justifications for addressing values. Other times, this involves using existing technical design practices like personas, but subverting them to foreground thinking about values such as accessibility. Or sometimes this involves using organizational principles to justify a wide variety of (not always sanctioned) actions that can be framed as advancing those principles. Moving amongst these practices, the interviewed UX professionals can take on different roles-researcher, advocate, privileged technology worker, laborer, and so forth.

The lens of soft resistance to analyze UX professionals' practices expands prior frameworks such as ethical mediation [26] or ethical design complexity $[12,26]$. While these approaches also look at how designers' practices are intertwined with organization power, ethical mediation and ethical design complexity focus on how values and ethics emerge as a part of designers' everyday technical design practice. Soft resistance builds on this by bringing attention to how some UX professionals view their values work as leading to potential organizational change. This draws some similarities to Winter and Saunders' discussion of the political power of bottom-up everyday actions in professional work, which can serve to reinforce or undermine and change existing policies [69]. The goals of UX professionals engaging in tactics of soft resistance are about creating organizational change that flows upward from everyday actions. Their goals go beyond creating more ethical products. Instead they also aim to create organizations that promote the values and ethics they desire.

The fact that some of the tactics of soft resistance share similarities with practices of everyday ethics such as such as trying to create a business case or educate other stakeholders [12] can be productive. These practices are similar, but may have different political commitments: everyday ethics has a commitment to creating more ethical products; while soft resistance has a commitment to contesting, critiquing, and creating a more ethical company. The similarities suggest that practices that are already common among UX professionals could be meaningfully repurposed towards new forms of organizational change, should the workers wish to embody their work with those politics The framing of resistance may also help researchers consider UX professionals' power and politics as collectives, rather than individuals, in future work.

Soft resistance shows how workers within tech companies can complement external groups' practices of critique, contestation, and change. This can help create new social networks of connection or solidarity in the broader project of critiquing the politics of the technology industry [64]. Recognizing the partiality of change-from-within practices, UX professionals' practices of soft resistance within organizations can complement external legal, political, social, academic, and community efforts that seek to change and re-imagine how large technology companies are configured. 


\subsection{Implications for Values in Design Research \& Practice}

This paper's investigation complements other research on the values in design and on the practices of those who produce and maintain technologies [26, 41, 55, 61]. This paper's findings open up and suggest a new design space for those researching values and ethics in design: rather than designing new tools and methods to be adopted into the design process, researchers and designers can design for the social and organizational aspects of UX professionals' values work. What might worker-centered design approaches [17] to UX professionals' values work look like?

Common existing design approaches from CSCW and HCI use design to try to solve a values problem, or to elicit values from stakeholders that can then be designed for [70]. Design tools created as a part of frameworks such as value sensitive design tend to focus on incorporating consideration of values into different stages of existing product design processes [21]. These approaches are useful and needed. However, the analysis of interviewees' tactics of soft resistance shows how work attempting to address values and create change also occurs outside of the product design process. This might involve designing for collective worker action within technology companies, tools to help UX professionals educate other organizational stakeholders, or creating tools and processes that are tactically and subversively legible to executives and managers while still addressing the values issues that UX professionals in an organization advocate for.

This paper's findings suggest the need for tools, practices, and structures that place responsibilities for values in collectives beyond the individual UX professional. Tools like codes of ethics or frameworks of ethical decision making presume that individual technology workers have the agency and authority to make or contest values and ethics decisions. This is not always the case. Design decisions may be made by management or other organizational stakeholders, or an individual's invocation of a shared value might be disputed by someone else's interpretation of that value. Even the individual decision to not work on a project for ethical reasons might result in the company firing that worker and assigning someone else to do the work instead. This suggests a need to design for collective responsibility for values and ethics, and educate students in technical fields (such as HCI) about collective action and responsibility.

The development of new value sensitive design and values in design tools might better consider the positionality of the technologists who are imagined to use those tools. Many design tools imagine that an empowered designer can adopt those tools within the design process to create more ethical products. However, these often do not account for the lack of power that UX professionals face in many companies. The value and legitimacy of their expertise may be questioned, the emotional and gendered aspects of their labor go unrecognized, and tech workers who push too hard regarding values and ethical issues can be fired and dismissed [10,44]. The design of new values and ethics methods and tools could be improved by considering designers' specific positionalities. For instance, if designing tools for the UX professionals interviewed in this study, one might consider how North American technology workers are largely not unionized, dependent on their employers for social benefits, and have relatively little recourse if fired. What risks might a UX professional raise by raising ethical issues in this context? Technology workers in other contexts may present different considerations for the design of values and ethics tools.

In suggesting implications for design, I recognize that "design" has rhetorical power and its own histories and politics $[32,57,63]$. Design itself is a partial practice; it will not solve all the problems that UX professionals encounter when attempting to do values work. Yet, the analysis of their practices as soft resistance highlights potential places where design interventions might help further UX professionals' values work and help work towards goals of organizational change.

Furthermore, many technology companies increasingly have ethics owners, people who hold responsibility for ethics and values across multiple parts of an organization [43]. This might include 
roles such as Chief Ethics Officer, Chief Diversity Officer, or Chief Privacy Officer. There may be some temptation to view technology company workforces and frontline workers as deficient in thinking about values and ethical issues. However, this assumption overlooks the frontline technology professionals who are already doing values work. Ethics owners can help empower these workers and involve them in broader organizational processes around ethics, such as by providing resources and compensation, a platform for their work, or job titles and visibility. When creating organizational structures and programs for values and ethics more broadly, UX professionals may serve as qualified candidates for staffing these roles. Their expertise in using design-based and human-centered methods and practices to attend to values can complement professionals with expertise in law, human rights, and other relevant fields.

The tactics described in this paper can serve as a starting point for UX professionals seeking to enact organizational change in looking for potential points of intervention. However, due to the focused sample of this paper, it is possible that not all of the tactics discussed in this paper will generalize to other work contexts. Observations and most interviewees were located in the San Francisco Bay Area and Silicon Valley; these geographic proximities may allow UX professionals to build social relations and share information with each other in ways that do not extend to other regions. Beyond this paper's study of UX professionals at large U.S. technology companies, there is still a need to understand the intersection of resistance tactics and values work in the practices of other groups involved in the production and maintenance of technical systems, such as UX professionals situated in other contexts, or other technologists like developers and product managers. Future research may also consider differences in practices conducted at different sized companies or in other regions within and beyond the United States. While this paper primarily focused on how a group of UX professionals viewed their own practices, future research may look more closely at the efficacy of different workers' tactics and different theories of change within technology companies.

\section{CONCLUSION}

Using the lens of soft resistance, this paper studies a network of UX professionals and the interaction of their values work with their attempts to enact organizational change. In attempting to enact organizational changes from positions within companies, these UX professionals reported making use of tactics that challenge some dominant assumptions and logics present in technology companies, while tactically making use of others, to try to achieve the ends they seek. Sometimes these tactics succeed, other times they fail, leading to feelings of both hope and skepticism in their ability to create meaningful change to address values.

While I characterize these practices as partial or "soft", addressing values and ethics issues is always partial, whether done through technical, social, institutional, or political processes. The tensions expressed between skepticism and hope recognize that no single action will solve all values and ethics problems. Attempting to this work from within technology companies and from within systems of power is challenging, but not necessarily futile. Recognizing points of intervention to enact change from within systems of power helps opens up a space of potential actions and alliances that UX professionals, researchers, designers, and academics can engage in from their respective subject positions.

\section{ACKNOWLEDGMENTS}

Thank you to the participants for sharing their experiences. Thank you to Deirdre Mulligan and Jenna Burrell for their guidance and feedback on this project. Conversations and feedback from many people helped shape this paper including: John Chuang, Gail DeKosnik, Sijia Xiao, Noura Howell, Nick Merrill, Zoe Kahn, Anne Jonas, Elizabeth Resor, Daniel Griffin, Emma Lurie, the 
Berkeley Algorithmic Fairness and Opacity Group, participants in the Spring 2020 Berkeley I School Doctoral Research and Theory Workshop, and the anonymous reviewers. This work was supported in part by funding from the National Science Foundation (SES 1650589) and the NSF Graduate Research Fellowship Program (DGE 1752814). Any opinions, findings, and conclusions or recommendations expressed in this material are those of the author and do not necessarily reflect those of the National Science Foundation.

\section{REFERENCES}

[1] Norah Abokhodair, Adam Hodges, and Sarah Vieweg. 2017. Photo Sharing in the Arab Gulf: Expressing the Collective and Autonomous Selves. In Proceedings of the 2017 ACM Conference on Computer Supported Cooperative Work and Social Computing - CSCW'17. ACM Press, New York, New York, USA, 696-711. https://doi.org/10.1145/2998181.2998338

[2] Sara Ahmed. 2019. A Complaint Biography. Biography 42, 3 (2019), 514-523. https://doi.org/10.1353/bio.2019.0057

[3] Madeleine Akrich. 1992. The De-Scription of Technical Objects. In Shaping Technology Building Society: Studies in Sociotechnical Change, Wiebe Bijker and John Law (Eds.). MIT Press, Cambridge, Massachusetts, Chapter 7, $205-224$.

[4] Tamara Alsheikh, Jennifer A. Rode, and Siân E. Lindley. 2011. (Whose) value-sensitive design? A study of long-distance relationships in an arabic cultural context. In Proceedings of the ACM 2011 conference on Computer supported cooperative work - CSCW'11. ACM Press, New York, New York, USA, 75. https://doi.org/10.1145/1958824.1958836

[5] Karla Badillo-Urquiola, Yaxing Yao, Oshrat Ayalon, Bart Knijnenurg, Xinru Page, Eran Toch, Yang Wang, and Pamela J. Wisniewski. 2018. Privacy in Context: Critically Engaging with Theory to Guide Privacy Research and Design. In Companion of the 2018 ACM Conference on Computer Supported Cooperative Work and Social Computing. ACM, New York, NY, USA, 425-431. https://doi.org/10.1145/3272973.3273012

[6] Stephanie Ballard, Karen M. Chappell, and Kristen Kennedy. 2019. Judgment Call the Game: Using value sensitive design and design fiction to surface ethical concerns related to technology. In Proceedings of the 2019 on Designing Interactive Systems Conference - DIS '19. ACM Press, New York, New York, USA, 421-433. https://doi.org/10.1145/33222276.3323697

[7] Eric P S Baumer and Jed R Brubaker. 2017. Post-userism. In Proceedings of the 2017 CHI Conference on Human Factors in Computing Systems - CHI '17. ACM Press, New York, New York, USA, 6291-6303. https://doi.org/10.1145/3025453. 3025740

[8] Kathy Baxter. 2018. How to Build Ethics into AI - Part I Research-based recommendations to keep humanity in AI. https://blog.einstein.ai/how-to-build-ethics-into-ai-part-iresearch-based-recommendations-to-keep-humanityin-ai/

[9] Jenna Burrell. 2009. The Field Site as a Network: A Strategy for Locating Ethnographic Research. Field Methods 21, 2 (feb 2009), 181-199. https://doi.org/10.1177/1525822X08329699

[10] Julia Carrie Wong. 2019. Fifth Google worker-activist fired in a month says company is targeting the vulnerable. https:/www.theguardian.com/us-news/2019/dec/17/fifth-google-worker-activist-fired-in-a-month-sayscompany-is-targeting-the-vulnerable

[11] Shruthi Sai Chivukula, Ziqing Li, Anne C. Pivonka, Jingning Chen, and Colin M. Gray. 2021. Surveying the Landscape of Ethics-Focused Design Methods. (2021), 28 pages. arXiv:2102.08909 http://arxiv.org/abs/2102.08909

[12] Shruthi Sai Chivukula, Chris Rhys Watkins, Rhea Manocha, Jingle Chen, and Colin M. Gray. 2020. Dimensions of UX Practice that Shape Ethical Awareness. In Proceedings of the 2020 CHI Conference on Human Factors in Computing Systems. ACM, New York, NY, USA, 1-13. https://doi.org/10.1145/3313831.3376459

[13] Michel de Certeau. 1984. The practice of everyday life. University of California Press, Berkeley. file://catalog.hathitrust. org/Record/000361088http://hdl.handle.net/2027/dul1.ark:/13960/t79s6x01c

[14] Anthony Dunne and Fiona Raby. 2001. Design Noir: The Secret Life of Electronic Objects. Vol. 1. Birkhauser. 176 pages.

[15] Mary Flanagan, Daniel C. Howe, and Helen Nissenbaum. 2008. Embodying values in technology: Theory and practice. In Information technology and Moral Philosophy, Jeroen Van Den Hoven and John (Charles Sa Weckert (Eds.). Cambridge University Press, New York, Chapter 16, 322-353. http://medcontent.metapress.com/index/A65RM03P4874243N pdfhttp://books.google.com/books?hl=en $\{\&\} \mathrm{lr}=\{\&\}$ id=K3ziD9zQrMAC $\{\&\}$ oi=fnd $\{\&\}$ pg=PA322 $\{\&\}$ dq=Embodying+ Values+in+Technology+Theory+and+Practice $\{\&\}$ ots=OOnoemmbWI $\{\&\}$ sig=x8XGCzLk81Eb0qR9rgvFmbyxU-s

[16] Kenneth R. Fleischmann, Sherri R. Greenberg, Danna Gurari, Abigale Stangl, Nitin Verma, Jaxsen R. Day, Rachel N. Simons, and Tom Yeh. 2019. Good Systems: Ethical AI for CSCW. In Conference Companion Publication of the 2019 on Computer Supported Cooperative Work and Social Computing. ACM, New York, NY, USA, 461-467. https: //doi.org/10.1145/3311957.3359437

[17] Sarah E. Fox, Vera Khovanskaya, Clara Crivellaro, Niloufar Salehi, Lynn Dombrowski, Chinmay Kulkarni, Lilly Irani, and Jodi Forlizzi. 2020. Worker-Centered Design: Expanding HCI Methods for Supporting Labor. In Extended Abstracts of the 2020 CHI Conference on Human Factors in Computing Systems. ACM, New York, NY, USA, 1-8. https://doi.org/10.1145/3334480.3375157 
[18] Diana Freed, Sam Havron, Emily Tseng, Andrea Gallardo, Rahul Chatterjee, Thomas Ristenpart, and Nicola Dell. 2019. "Is my phone hacked?" Analyzing Clinical Computer Security Interventions with Survivors of Intimate Partner Violence. Proceedings of the ACM on Human-Computer Interaction 3, CSCW (nov 2019), 1-24. https://doi.org/10.1145/3359304

[19] Batya Friedman. 1996. Value-sensitive design. Interactions 3, 6 (1996), 16-23. https://doi.org/10.1145/242485.242493

[20] Batya Friedman and David Hendry. 2012. The envisioning cards: a toolkit for catalyzing humanistic and technical imaginations. In Proceedings of the 2012 ACM annual conference on Human Factors in Computing Systems (CHI '12) ACM Press, New York, New York, USA, 1145-1148. https://doi.org/10.1145/2207676.2208562

[21] Batya Friedman, David G. Hendry, and Alan Borning. 2017. A Survey of Value Sensitive Design Methods. Foundations and Trends ${ }^{\circledR}$ in Human-Computer Interaction 11, 2 (2017), 63-125. https://doi.org/10.1561/1100000015

[22] Erin Friess. 2012. Personas and decision making in the design process: An Ethnographic Case Study. In Proceedings of the 2012 ACM annual conference on Human Factors in Computing Systems - CHI '12. ACM Press, New York, New York, USA, 1209. https://doi.org/10.1145/2207676.2208572

[23] Karin Garrety and Richard Badham. 2004. User-Centered Design and the Normative Politics of Technology. Science, Technology, \& Human Values 29, 2 (apr 2004), 191-212. https://doi.org/10.1177/0162243903261946

[24] Google PAIR. 2019. People + AI Guidebook. https://pair.withgoogle.com/guidebook/

[25] Colin M. Gray. 2014. Evolution of design competence in UX practice. In Proceedings of the 32nd annual ACM conference on Human factors in computing systems - CHI '14. ACM Press, New York, New York, USA, 1645-1654. https://doi.org/ 10.1145/2556288.2557264

[26] Colin M. Gray and Shruthi Sai Chivukula. 2019. Ethical Mediation in UX Practice. In Proceedings of the 2019 CHI Conference on Human Factors in Computing Systems - CHI '19. ACM Press, New York, New York, USA, 1-11. https: //doi.org/10.1145/3290605.3300408

[27] Daniel Greene, Anna Lauren Hoffmann, and Luke Stark. 2019. Better, Nicer, Clearer, Fairer: A Critical Assessment of the Movement for Ethical Artificial Intelligence and Machine Learning. In Proceedings of the 52nd Hawaii International Conference on System Sciences. https://doi.org/10.24251/HICSS.2019.258

[28] Seda Gürses and Joris Van Hoboken. 2017. Privacy After the Agile Turn. In Cambridge Handbook of Consumer Privacy, Jules Polonetsky, Omer Tene, and Evan Selinger (Eds.). Cambridge University Press. https://doi.org/10.31235/osf.io/ 9 gy73

[29] Arlie Russell Hochschild. 1983. The Managed Heart: Commercialization of Human Feeling. University of California Press, Berkeley, CA.

[30] Anna Lauren Hoffmann. 2020. Terms of inclusion: Data, discourse, violence. New Media \& Society (sep 2020), 146144482095872. https://doi.org/10.1177/1461444820958725

[31] Lara Houston, Steven J Jackson, Daniela K Rosner, Syed Ishtiaque Ahmed, Meg Young, and Laewoo Kang. 2016. Values in Repair. In Proceedings of the 2016 CHI Conference on Human Factors in Computing Systems - CHI '16. ACM Press, New York, New York, USA, 1403-1414. https://doi.org/10.1145/2858036.2858470

[32] Lilly Irani. 2018. "Design Thinking": Defending Silicon Valley at the Apex of Global Labor Hierarchies. Catalyst: Feminism, Theory, Technoscience 4, 1 (2018), 1-19. https://doi.org/10.28968/cftt.v4i1.29638

[33] Vera Khovanskaya, Lynn Dombrowski, Jeffrey Rzeszotarski, and Phoebe Sengers. 2019. The Tools of Management: Adapting Historical Union Tactics to Platform-Mediated Labor. Proceedings of the ACM on Human-Computer Interaction 3, CSCW (nov 2019), 1-22. https://doi.org/10.1145/3359310

[34] Vera Khovanskaya and Phoebe Sengers. 2019. Data Rhetoric and Uneasy Alliances: Data Advocacy in US Labor History. In Proceedings of the 2019 on Designing Interactive Systems Conference. ACM, New York, NY, USA, 1391-1403. https://doi.org/10.1145/3322276.3323691

[35] Airi Lampinen, Christoph Lutz, Gemma Newlands, Ann Light, and Nicole Immorlica. 2018. Power Struggles in the Digital Economy: Platforms, Workers, and Markets. In Companion of the 2018 ACM Conference on Computer Supported Cooperative Work and Social Computing. ACM, New York, NY, USA, 417-423. https://doi.org/10.1145/3272973.3273004

[36] Christopher A. Le Dantec, Erika Shehan Poole, and Susan P. Wyche. 2009. Values as lived experience: Evolving value sensitive design in support of value discovery. In Proceedings of the 27th international conference on Human factors in computing systems - CHI 09. ACM Press, New York, New York, USA, 1141. https://doi.org/10.1145/1518701.1518875

[37] Min Kyung Lee, Daniel Kusbit, Evan Metsky, and Laura Dabbish. 2015. Working with Machines: The Impact of Algorithmic and Data-Driven Management on Human Workers. Proceedings of the ACM CHI'15 Conference on Human Factors in Computing Systems 1 (2015), 1603-1612. https://doi.org/10.1145/2702123.2702548

[38] Silvia Lindtner, Shaowen Bardzell, and Jeffrey Bardzell. 2018. Design and intervention in the age of "no alternative". Proceedings of the ACM on Human-Computer Interaction 2, CSCW (2018). https://doi.org/10.1145/3274378

[39] John Lofland, David Snow, Leon Anderson, and Lyn Lofland. 2006. Analyzing Social Settings: A guide to qualitaitve observation and analysis (4th ed.). Wadsworth, Belmont, CA.

[40] Ewa Luger, Lachlan Urquhart, Tom Rodden, and Michael Golembewski. 2015. Playing the Legal Card: Using Ideation Cards to Raise Data Protection Issues within the Design Process. In Proceedings of the 33rd Annual ACM Conference 
on Human Factors in Computing Systems - CHI '15, Vol. 1. ACM Press, New York, New York, USA, 457-466. https: //doi.org/10.1145/2702123.2702142

[41] Michael A. Madaio, Luke Stark, Jennifer Wortman Vaughan, and Hanna Wallach. 2020. Co-Designing Checklists to Understand Organizational Challenges and Opportunities around Fairness in AI. In Proceedings of the $2020 \mathrm{CHI}$ Conference on Human Factors in Computing Systems. ACM, New York, NY, USA, 1-14. https://doi.org/10.1145/3313831. 3376445

[42] Nick Merrill. 2020. Security Fictions: Bridging Speculative Design and Computer Security. In Proceedings of the 2020 ACM Designing Interactive Systems Conference. ACM, New York, NY, USA, 1727-1735. https://doi.org/10.1145/3357236 3395451

[43] Jacob Metcalf, Emanuel Moss, and danah Boyd. 2019. Owning ethics: Corporate logics, Silicon Valley, and the institutionalization of ethics. Social Research 86, 2 (2019), 449-476.

[44] Cade Metz and Daisuke Wakabayashi. 2020. Google Researcher Says She Was Fired Over Paper Highlighting Bias in A.I. https://www.nytimes.com/2020/12/03/technology/google-researcher-timnit-gebru.html

[45] Microsoft. 2020. Responsible AI Resources. https://www.microsoft.com/en-us/ai/responsible-ai-resources

[46] Microsoft Design. 2016. Inclusive Microsoft Design. 24 pages. https://download.microsoft.com/download/b/0/d/b0d4bf8709ce-4417-8f28-d60703d672ed/inclusive_toolkit_manual_final.pdf

[47] Michael Muller. 2014. Whose Values? Whose Design? (2014). http://ethicsworkshopcscw2014.files.wordpress.com/ 2013/10/muller-whose-values.pdf

[48] Deirdre K. Mulligan, Joshua A. Kroll, Nitin Kohli, and Richmond Y. Wong. 2019. This Thing Called Fairness: Disciplinary confusion realizing a value in technology. Proceedings of the ACM on Human-Computer Interaction 3, CSCW (nov 2019), 1-36. https://doi.org/10.1145/3359221 arXiv:1909.11869

[49] Dawn Nafus and Ken Anderson. 2006. The Real Problem: Rhetorics of Knowing in Corporate Ethnographic Research. Ethnographic Praxis in Industry Conference Proceedings 2006, 1 (sep 2006), 244-258. https://doi.org/10.1111/j.15598918.2006.tb00051.x

[50] Dawn Nafus and Jaime Sherman. 2014. This One Does Not Go Up to 11: The Quantified Self Movement as an Alternative Big Data Practice. International fournal of Communication 8 (2014), 1-11.

[51] Lisa P. Nathan, Batya Friedman, Predrag Klasjna, Shaun K. Kane, and Jessica K. Miller. 2008. Envisioning systemic effects on persons and society throughout interactive system design. Proceedings of the 7th ACM Conference on Designing Interactive Systems (DIS '08) (2008), 1-10. https://doi.org/10.1145/1753846.1754003

[52] Helen Nissenbaum. 2001. How computer systems embody values. Computer 34, 3 (mar 2001), 120-119. https: //doi.org/10.1109/2.910905

[53] Julian E. Orr. 1996. Talking About Machines: An Ethnography of a Modern fob. ILR Press/Cornell University Press, Ithaca, NY.

[54] Nassim Parvin, Lisa Nathan, and Ian Hargraves. 2015. Values as Hypotheses: Design, Inquiry, and the Service of Values. Design Issues 31, 4 (oct 2015), 91-104. https://doi.org/10.1162/DESI_a_00354

[55] Samir Passi and Steven J Jackson. 2018. Trust in Data Science: Collaboration, Translation, and Accountability in Corporate Data Science Projects. Proceedings of the ACM on Human-Computer Interaction 2, CSCW (nov 2018), 1-28. https://doi.org/10.1145/3274405

[56] Emma Rose and Josh Tenenberg. 2016. Arguing about design: A taxonomy of rhetorical strategies deployed by user experience practitioners. In Proceedings of the 34th ACM International Conference on the Design of CommunicationSIGDOC '16. ACM Press, New York, New York, USA, 1-10. https://doi.org/10.1145/2987592.2987608

[57] Daniela K. Rosner. 2018. Critical Fabulations: Reworking the Methods and Margins of Design. The MIT Press, Cambridge, Massachusetts.

[58] Johnny Saldaña. 2013. The Coding Manual for Qualitative Researchers (2nd ed.). Sage, Los Angeles.

[59] James C. Scott. 1998. Seeing Like a State: How certain schemes to improve the human condition have failed. Yale University Press, New Haven.

[60] Katie Shilton. 2010. Technology development with an agenda: Interventions to emphasize values in design. Proceedings of the American Society for Information Science and Technology 47, 1 (nov 2010), 1-10. https://doi.org/10.1002/meet. 14504701040

[61] Katie Shilton. 2013. Values Levers: Building Ethics into Design. Science, Technology, \& Human Values 38, 3 (2013), 374-397. https://doi.org/10.1177/0162243912436985

[62] Katie Shilton, Jes A. Koepfler, and Kenneth R. Fleischmann. 2014. How to see values in social computing: Methods for Studying Values Dimensions. In Proceedings of the 17th ACM Conference on Computer Supported Cooperative Work \& Social Computing (CSCW'14). ACM Press, New York, New York, USA, 426-435. https://doi.org/10.1145/2531602.2531625

[63] Christo Sims. 2017. The Politics of Design, Design as Politics. In The Routledge Companion to Digital Ethnography, Larissa Hjorth, Heather Horst, Anne Galloway, and Genevieve Bell (Eds.). Routledge, New York, Chapter 40, 439-447. 
[64] Norman Makoto Su, Amanda Lazar, and Lilly Irani. 2021. Critical Affects: Tech Work Emotions Amidst the Techlash. Proceedings of the ACM on Human-Computer Interaction 5, CSCW1 (2021), 1-27. https://doi.org/10.1145/3449253

[65] Stefan Timmermans and Iddo Tavory. 2012. Theory construction in qualitative research: From grounded theory to abductive analysis. Sociological Theory 30, 3 (2012), 167-186. https://doi.org/10.1177/0735275112457914 arXiv:arXiv:1011.1669v3

[66] Kristen Vaccaro, Karrie Karahalios, Deirdre K. Mulligan, Daniel Kluttz, and Tad Hirsch. 2019. Contestability in Algorithmic Systems. In Conference Companion Publication of the 2019 on Computer Supported Cooperative Work and Social Computing. ACM, New York, NY, USA, 523-527. https://doi.org/10.1145/3311957.3359435

[67] Alex Wilkie and Mike Michael. 2009. Expectation and Mobilisation: Enacting Future Users. Science, Technology, \& Human Values 34, 4 (jul 2009), 502-522. https://doi.org/10.1177/0162243908329188

[68] Langdon Winner. 1980. Do Artifacts Have Politics? Daedalus 109, 1 (1980), 121-136.

[69] Susan J. Winter and Carol Saunders. 2019. The personal in the policy cascade. fournal of the Association for Information Systems 20, 11 (2019), 1692-1699. https://doi.org/10.17705/1jais.00582

[70] Richmond Y. Wong and Deirdre K. Mulligan. 2019. Bringing Design to the Privacy Table: Broadening "Design" in "Privacy by Design" Through the Lens of HCI. In CHI Conference on Human Factors in Computing Systems (CHI 2019). https://doi.org/10.1145/3290605.3300492

[71] Richmond Y. Wong, Deirdre K Mulligan, Ellen Van Wyk, James Pierce, and John Chuang. 2017. Eliciting Values Reflections by Engaging Privacy Futures Using Design Workbooks. Proceedings of the ACM on Human Computer Interaction 1, CSCW (2017), 1-27. https://doi.org/10.1145/3134746

[72] Richmond Y. Wong and Tonya Nguyen. 2021. Timelines: A World-Building Activity for Values Advocacy. In Proceedings of the 2021 CHI Conference on Human Factors in Computing Systems. ACM, New York, NY, USA, 1-15. https://doi.org/ 10.1145/3411764.3445447

[73] Steve Woolgar. 1990. Configuring the User: The Case of Usability Trials. The Sociological Review 38, 1_suppl (may 1990), 58-99. https://doi.org/10.1111/j.1467-954X.1990.tb03349.x

[74] Yaxing Yao, Richmond Wong, Pardis Emami-Naeini, Nick Merrill, Xinru Page, Yang Wang, and Pamela Wisniewski. 2019. Ubiquitous Privacy: Research and Design for Mobile and IoT Platforms. In CSCW'19 Companion. ACM. https: //doi.org/10.1145/3311957.3359430

[75] Shoshana Zuboff. 1988. In the Age of the Smart Machine: The Future of Work and Power. Basic Books, New York.

Received October 2020; revised April 2021; accepted July 2021 